\title{
Strategies for Translation of Similes in Four Different Persian Translations of Hamlet
}

\author{
Mansour Shamsaeefard ${ }^{1, *}$, Mohammad Reza Falahati Qadimi Fumani ${ }^{2}$, Azadeh Nemati ${ }^{3}$ \\ ${ }^{1}$ Department of English Translation, Science and Research Branch, Islamic Azad University, Fars, Iran \\ ${ }^{2}$ Department of Computational Linguistics, Regional Information Center for Science and Technology, Shiraz, Iran \\ ${ }^{3}$ Department of English Language Teaching, Jahrom Branch, Islamic Azad University, Jahrom, Iran \\ *Corresponding Author: mshamsaeefard@gmail.com
}

Copyright (C) 2013 Horizon Research Publishing All rights reserved.

\begin{abstract}
The present study aimed at examining four different Persian translations of Hamlet to find out the strategies used for translation of similes based on the strategy model proposed by Pierini (2007). The Persian translations selected were those by Beh Azin, Farzad, Pasargadi and Shahin. To collect the relevant data, the whole original text of Hamlet was read thoroughly and finally 85 examples of similes were extracted from it. Later, through comparing the English similes and their Persian equivalents, the type of strategy used for each simile was determined. The results indicated that from among the six strategies proposed by Pierini, all the translators had applied the first strategy, literal translation, much more than the other ones. Meanwhile, none of the translators had used reduction of the simile, if idiomatic, to its sense in their work. Further, very low application of retention of the same vehicle plus explicitation of similarity feature(s) and replacement of the vehicle with a gloss was reported in the four translations. To answer the second research question, Chi-square test was drawn on to find out whether there was a statistically significant difference in the application of each strategy in the four translations. The results indicated that there were no statistically significant differences in the application of strategies in the four translations of Hamlet meaning that the four translators had used the strategies similarly.
\end{abstract}

Keywords Literary Translation, Translation Strategies, Pierini's Model, Simile Translation, Hamlet

\section{Introduction}

It is hard to find a language in which no use is made of figures of speech. Throughout history, humans have introduced figures of speech into their languages to make their thought more vivid and their narration more intelligible and accurate. Naturally, then, simile was doubtless one of the first figures used.

There have been few researches focusing on simile distinctly. In fact, simile has often been discussed along with metaphor or other literary devices. However, similes deserve attention in their own part and further studies regarding their nature and the mechanisms of their translation seem necessary and of paramount importance.

Although similes seem easily recognizable, their translation can, at times, be a real challenge and, accordingly, in need of careful attention. Pierini (2007) studied and described similes in English. She indicated some potential strategies to translate similes. They are:

$\mathrm{S}_{1}$ : literal translation (retention of the same vehicle)

$\mathrm{S}_{2}$ : replacement of the vehicle with a different vehicle

$\mathrm{S}_{3}$ : reduction of the simile, if idiomatic, to its sense

$\mathrm{S}_{4}$ : retention of the same vehicle plus explicitation of similarity feature(s)

$\mathrm{S}_{5}$ : replacement of the vehicle with a gloss

$\mathrm{S}_{6}$ : omission of the simile. (p. 31)

Regarding the fifth strategy, the source vehicle is replaced with a gloss in translation. According to Pierini (2007), it is the case when the vehicle is a proper name representing a cultural allusion. According to Leppihalme (as cited in Pierini, 2007), "Allusions (e.g. literary quotations and references to people, places, events, songs and films) are culture-bound elements whose interpretation depends on world knowledge" (p. 34). Pierini states if the translator believes that the target readership has the required background knowledge to interpret the simile, s/he can leave the simile unchanged; if the target readership does not, some modification to the source simile may be needed, for example, adding some explanatory information.

Besides Pierini (2007), Larson (1984) also proposes ways to translate similes. However, Pierini's model has been selected as the framework of this study because, compared to Larson's, it seems more comprehensive and efficient. In fact, it provides more options and more various possibilities for simile translation.

This article focuses on Hamlet - Shakespeare's masterpiece and one of the great tragedies in the world - to find out the ways similes have been translated in this particular literary genre. The researcher will analyze simile 
translation strategies in four different translations of Hamlet on the basis of the strategies proposed by Pierini (2007). This article attempts to answer the following questions:

1. What are the strategies applied in the translation of similes in four different Persian translations of Hamlet?

2. Is there a statistically significant difference in the application of each strategy in four different translations of Hamlet?

The second research question was approached as a null hypothesis; that is, there is no significant difference in the application of each strategy in four different translations of Hamlet.

\section{Literature Review}

Simile is one of the most frequently occurring and natural sounding parts of figurative language. No one would argue about the important role of similes especially in literary texts. Not many studies can be found focusing on simile, but this figure of speech can be traced in a number of useful sources although most of them have often discussed it along and in comparison with metaphor.

Abrams and Harpham (2012), in their book, discuss simile in brief as a figure of thought and under the heading of figurative language. In defining simile, they state, "In a simile, a comparison between two distinctly different things is explicitly indicated by the words 'like' or 'as"' (p. 130). They quote Burns', ' $\mathrm{O}$ my love is like a red, red rose', as an example.

In a research conducted by Tsõmbarevitš (2011), various definitions of simile by different scholars have been provided. In addition, the syntactic and semantic classifications of simile, distinguishing similes from other similar types of word groups and the issues related to translating similes are discussed.

In a paper, O'Donoghue (2009) compares simile and metaphor and attempts to show that metaphor and simile are different in meaning, in effect and in the way they are processed, and believes, “...these differences are all due to a fundamental bias in the form of the simile towards the terms of the comparison being made" (p. 129).

In her paper, Pierini (2007) discusses the nature and function of similes, the criteria for their classification, and their interpretation. According to her, simile can be defined as "...the statement of a similarity relation between two entities, essentially different but thought to be alike in one or more respects, or a non-similarity relation" (p. 23). As for the parts of a simile, she quotes Fromilhague and states:

Simile has a tripartite structure, consisting of: 'topic', or comparandum, (the entity described by the simile); 'vehicle', or comparatum, (the entity to which the topic is compared), accompanied by a comparison marker; 'similarity feature(s)' (the properties shared by topic and vehicle), which can be expressed explicitly or left unsaid. (p. 23)

Of course, topic is also referred to as 'tenor' (e.g. Abrams \& Harpham, 2012, p. 131) and vehicle as 'image' (e.g.
Newmark, 1988, p. 85; Larson, 1998, p. 272).

Israel, Harding and Tobin (2004) discuss simile and metaphor as distinguished figures and try to prove simile as a figure in its own right, and as an object of study distinct both from metaphorical expression and literal comparison.

In part of her book, Larson (1984) also studies simile and metaphor together. According to her, a metaphor or simile has four parts including 'topic', 'image', 'point of similarity' and 'nonfigurative equivalent'. She also divides simile and metaphor into dead and live categories. Finally, she proposes five ways to translate metaphors of which three can be applied to translation of similes. They are: (1) Substitute a simile of the receptor language which has the same meaning; (2) keep the same simile and explain the meaning, that is, the topic and/or point of similarity may be added; and (3) translate the meaning of the simile without keeping the metaphorical imagery.

\section{Methodology}

\subsection{Materials of the Study}

Shakespeare's tragedy of Hamlet and four of its Persian translations made up the materials of the present study. An electronic version of Hamlet (2011) was chosen as the original text. To ensure that there were no lexical-textual differences, the extracts containing similes taken from this version were later cross-validated against another electronic version (The Complete Works of William Shakespeare, 2012) and Adib-Soltani's (2010) version, taken from The Arden Shakespeare edited by Harold Jenkins, in his bilingual text.

The Persian translations selected are those by Beh Azin, Farzad, Pasargadi and Shahin. The Persian versions used were deemed as the most well-known translations of Hamlet. This tragedy has also been translated by other famous translators and writers (e.g. Hekmat, 1956; Rahimi, 1992; Fasih, 1997) whose translations have been either synopsis or adaptation for which reason they were excluded from the present study. Adib-Soltani also translated Hamlet in 2006, but he drew on Old and Middle Persian in his translation. Therefore, his translation, also, was excluded from this study.

\subsection{Procedure of the Study}

To carry out the present research, the following steps were taken. First, the tragedy of Hamlet was chosen as the main data source. The researcher browsed the Web and selected an electronic version of Hamlet. Then, all its available Persian translations were identified. Among them, those translated completely as a play, those by Beh Azin, Farzad, Pasargadi and Shahin, were selected.

Then, to collect the relevant data, the whole original text of Hamlet, consisting of five acts and twenty scenes, was read thoroughly to extract similes. At this point, a researcher holding an M.A. degree in TEFL assisted in finding the 
similes. To do so, each act of the original text was read separately by the researcher and the M.A. expert and all instances of similes were extracted. Then, the two lists produced were compared to find out if there were any differences in the items reported. Mismatches between the two lists were further discussed for inclusion in or exclusion from the final data list. All the five acts were covered in this manner. This led to a list encompassing more than 100 potential similes. Afterwards, two experts - an M.A. and a Ph.D. holder in English Literature - separately, reviewed the list of similes for their accuracy. Some disagreements were found between the two raters on some cases. On such cases, the researcher had another Ph.D. holder in English Literature and a Professor in English Literature check them as well and the output on which both raters agreed were included in the final list of similes. This reduced the total number of similes, on the list, to 82 of which 3 contained two similes each simply meaning that the total number of similes on the finalized list was 85 .

Later, to analyze the data, Pierini's (2007) model was selected. She proposed six potential strategies to translate similes. Through comparing the English and Persian texts, the type of strategy used for each simile was determined. For further reliability, besides the present researcher an M.A. holder in English Translation also labeled the data based on the strategies introduced by Pierini. There were, of course, some differences between the two raters in terms of the strategies they selected. These problematic cases were further discussed between the two raters to reach an agreement as regards the strategy type identified. Finally, the data were analyzed statistically using SPSS version 16 . Both descriptive (in the form of frequency counts, tables and figures) and inferential statistics (Chi-square test) were used to answer the questions formulated earlier in this study.

\section{Data Analysis and Findings}

Before getting into the analysis, some abbreviations need to be introduced due to their widespread application throughout this section. Such abbreviations have been used for the sake of space and are as follows:

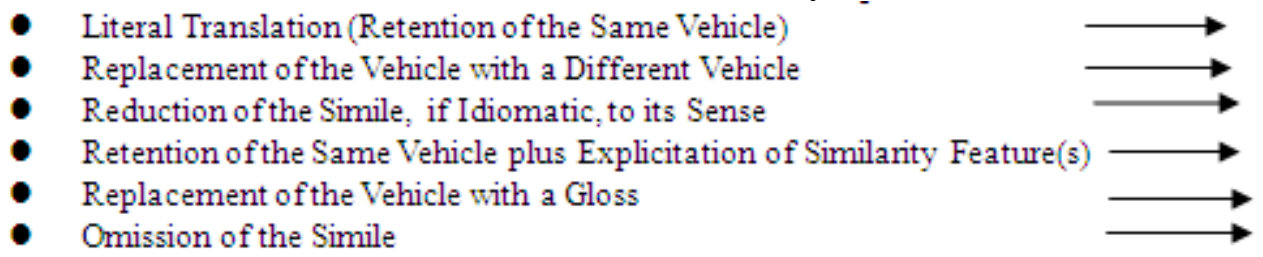

To answer the first research question, the strategies selected by translators to translate similes were first determined and tallied and the results obtained were presented in table form for each of the four translations. A summary table for all the translators is presented below.

As indicated in Table 4.1, the first strategy, $L T$, was the dominant strategy in all four translations. Compared to others, Beh Azin used this strategy more in his translation. In all four translations, $R V D V$, ranked second. The only strategy not used in any of the translations was the third one - RSIS. The fourth strategy, RSV+ESF, was not used in Farzad's and Shahin's translations, but Beh Azin and Pasargadi each applied it in one case. Except for Pasargadi who used the fifth strategy, $R V G$, for two cases, the others did not. Among the translators, Beh Azin was the only one who did not use the sixth strategy, $O S$, in his translation. The others omitted the simile in a few cases. All translators used strategies not included in Pierini's model. Compared to other translators, Beh Azin used such strategies least while Farzad used them most.

Table 4.1. Frequency (percentage) of simile translation strategies as applied in four translations

\begin{tabular}{|c|c|c|c|c|}
\hline Strategy & Beh Azin & Farzad & Pasargadi & Shahin \\
\hline $\begin{array}{l}\text { 1. Literal translation (retention of the same } \\
\text { vehicle) }\end{array}$ & $77(90.6 \%)$ & $63(74.15 \%)$ & $63(74.15 \%)$ & $63(74.15 \%)$ \\
\hline $\begin{array}{l}\text { 2. Replacement of the vehicle with a different } \\
\text { vehicle }\end{array}$ & $4(4.7 \%)$ & $6(7 \%)$ & $5(5.9 \%)$ & $7(8.2 \%)$ \\
\hline $\begin{array}{l}\text { 3. Reduction of the simile, if idiomatic, to its } \\
\text { sense }\end{array}$ & 0 & 0 & 0 & 0 \\
\hline $\begin{array}{l}\text { 4. Retention of the same vehicle plus } \\
\text { explicitation of similarity feature(s) }\end{array}$ & $1(1.18 \%)$ & 0 & 1 & 0 \\
\hline 5. Replacement of the vehicle with a gloss & 0 & 0 & $2(2.3 \%)$ & 0 \\
\hline 6. Omission of the simile & 0 & $4(4.7 \%)$ & $3(3.52 \%)$ & $4(4.7 \%)$ \\
\hline Other $*$ & $3(3.52 \%)$ & $12(14.15 \%)$ & $11(12.95 \%)$ & $11(12.95 \%)$ \\
\hline Total & $85(100 \%)$ & $85(100 \%)$ & $85(100 \%)$ & $85(100 \%)$ \\
\hline
\end{tabular}

*. 'Other' refers to strategies other than those proposed by Pierini such as changing the simile to a declarative (non-figurative) sentence, conveying the sense of the simile, changing the simile to an adjective, etc. Due to the diversity of such strategies, they were all grouped under the general term 'Other'. 
To answer the second research question, Chi-square test was utilized. For each of the six strategies in Pierini's model, as well as for the Other class, a separate Chi-square was planned to be computed, but given the low application of strategies 3, 4 and 5 in the four translations no Chi-square computation could be run for them and accordingly only four Chi-square tests (for strategies 1, 2, 6 \& Other) were computed in this part. The results have been reported below in a summary table.

Table 4.2. Chi-square test statistics for the application of strategies in the four translations

\begin{tabular}{|c|c|c|c|c|}
\hline Strategy & Beh Azin & Farzad & Pasargadi & Shahin \\
\hline LT & \multicolumn{4}{|c|}{ NS - df: 3, Asymp. Sig.: .550 } \\
\hline RVDV & \multicolumn{4}{|c|}{ NS - df: 3, Asymp. Sig.: .823 } \\
\hline OS & \multicolumn{4}{|c|}{ NS - df: 2, Asymp. Sig.: .913 } \\
\hline Other & \multicolumn{4}{|c|}{ NS - df: 3, Asymp. Sig.: .127 } \\
\hline
\end{tabular}

As indicated in table 4.2, the significance levels pertaining to strategies 1, 2, 6 and the Other class in the four translations are all more than 0.05 ; that is, there is no statistically significant difference in the application of each strategy in the four translations of Hamlet meaning that the four translators used the strategies similarly.

\section{Discussion and Conclusion}

The purpose of this study was to examine four Persian translations of Hamlet to investigate the strategies used for translation of similes based on the strategies suggested by Pierini (2007). It was also aimed to find out whether there was any significant difference in the application of each strategy in the four translations. The findings of the study show that among the six strategies proposed by Pierini to translate simile, the four translators applied the first strategy, literal translation, much more than the other strategies. Considering the fact that most of similes in Hamlet are 'creative similes', it seems that the translators tried to keep the figurative language of the source text resorting to literal translation. This is also in line with Pierini's (2007) idea regarding simile translation that reads, "The more the simile is divergent from current use of language, the stronger the case for literal translation, so that the target reader will be as puzzled as the source reader" (p. 38). In addition, it is in line with part of the results of a research conducted by Nourizadeh (2003). In his thesis, Nourizadeh examined different techniques of translating simile based on the techniques proposed by Ahmadian (2000). Besides other objectives sought by the researcher based on the results, the findings also indicated that the most frequently used technique, by both M.A. and B.A. students in his study, was 'appropriate translation' (literal translation).

Further, none of the translators used the third strategy, reduction of the simile, if idiomatic, to its sense. But the fact is that only few of the similes in Hamlet are idiomatic, for which the translators applied literal translation. In fact, translating those similes literally is quite natural and acceptable in the Persian language.

Among the six strategies, there were very low application of strategies 4 and 5, namely retention of the same vehicle plus explicitation of similarity feature(s) and replacement of the vehicle with a gloss. These two strategies were either avoided or were applied only in one or two cases by the translators. Regarding the sixth strategy, omission of the simile, unlike the other translators, Beh Azin left none of the similes untranslated in his work.

The findings also show that the translators in some cases resorted to strategies that did not match any of those proposed by Pierini (2007). These strategies were termed as Other and were the most frequently used ones in the translations after Pierini's first strategy. It indicates that in translating similes from English into Persian other strategies may also be applied. In fact, it shows incapability and deficiency of Pierini's model. These strategies should be examined in larger samples to provide a comprehensive list of them and embed them in Pierini's model to complete it. This way we can revise this model to have a more comprehensive and efficient model for translation of similes from English into Persian.The common types of such strategies in the translations are conveying the sense of the simile, change the simile to an adjective and change the simile to a noun phrase.

As regards the significance of difference in the application strategies, the results of the Chi-square test supported the hypothesis of the study; that is, there was no statistically significant difference in the application of each strategy in the four translations of Hamlet.

The present study, and studies alike, can help translators and translation students have a better understanding of figures of speech and the difficulties they can pose in translating, especially in literary texts. If different figures of speech are under scrutiny separately, the results may pave the way for new strategies to be formulated. Moreover, it is suggested that translation trainers, especially those of literary translation, design a syllabus in which students find opportunity to practice tackling literary translation problems based on specific techniques and strategies.

\section{REFERENCES}

[1] Abrams, M. H., \& Harpham, G. G. (2012). A glossary of literary terms (10th ed.). Boston, Mass.: Wadsworth Cengage Learning.

[2] Adib- Soltani. M. S. (2010). Soognemayesh-e Hamlet, shahpour-e danmark [The tragedy of Hamlet, prince of Denmark] (2nd ed.). Tehran: Negah Publishing House.

[3] Beh Azin, M. E. (1981). Hamlet (4th ed.). Tehran: Doran Publications. 
[4] Farzad, M. (2010). Hamlet (17th ed.). Tehran: Elmifarhangi Publications.

[5] Fasih, E. (2000). Hamlet. In Shakespeare: Life / Summary of all works / Hamlet (2nd ed.). Tehran: Peykan Publications.

[6] Hekmat, A. A. (2011). Qamnameh-ye Hamlet, shahzadeh-ye danmark [The tragedy of Hamlet, prince of Denmark]. In Panj hekayat [Five tales] (4th ed., pp. 196-238). Tehran: Qoqnoos Publications.

[7] Israel, M., Harding, J. R., \& Tobin, V. (2004). On simile. In M. Achard \& S. Kemmer (Eds.), Language, culture, and mind (pp.123-134). Stanford, CA: CSLI Publications.http://terpconnect.umd.edu/ israel/Israel\%26alSimile.pdf

[8] Larson, M. L. (1984). Figurative propositions/ metaphors and similes. In Meaning-based translation: A guide to cross-language equivalence (pp. 246-255). Lanham, Mar.: University Press of America.

[9] Newmark, P. (1988). Approaches to translation. Singapore: Prentice Hall.

[10] Nourizadeh, Y. (2003). Different techniques of translating simile. (Unpublished master's thesis). Islamic Azad University of Science and Research, Tehran Branch.

[11] O’Donoghue, J. (2009). Is a metaphor (like) a simile? Differences in meaning, effect and processing. Retrieved January 9, 2012, from http://www.ucl.ac.uk/psychlangsci/res earch/linguistics/publications/wpl/09papers/odonoghue

[12] Pasargadi, A. (2003). Hamlet, shahzadeh-ye danmark [Hamlet, prince of Denmark]. In Majmoue asar-e namayeshi-ye William Shakespeare [The complete plays of William Shakespeare (3rd ed., 2nd Vol., pp. 896- 984]. Tehran: Soroush Press.

[13] Pierini, P. (2007). Simile in English: From description to translation. CÍRCULO de Lingüistica Aplicada a la Comunicación (clac) 29, 21-43.

[14] Rahimi, M. (1992). Hamlet. Tehran: Roshangaran.

[15] Shahin, D. (1965). Hamlet. Tehran: Javidane Elmi Publications.

[16] Shakespeare, W. (n.d.). Hamlet. Retrieved October 31, 2011, from http://manybooks.net/titles/shakespeetext982ws2610.html

[17] Shakespeare, W. (n.d.). The tragedy of Hamlet, prince of Demark. In The complete works of William Shakespeare. Retrieved January 10, 2012, from http://shakespeare.mit.edu/

[18] Tsõmbarevitš, A. (2011). Translating similes in Haruki Murakami's novel 'Norwegian Wood'. (Published master's thesis). Retrieved February 25, 2012, from http://aveleen.com/HMsimiles.pdf 